Economics Development Analysis Journal 6(3)(2017) Economics Development Analysis Journal

\title{
Analisis Kebijakan Permukiman Liar di Sempadan Banjir Kanal Timur
}

\author{
Lavinia Elisa Berliana $^{1 凶}$, Amin Pujiati $^{2}$ \\ ${ }^{1} \mathrm{PT}$. Avico Internasional Indonesia \\ ${ }^{2}$ Jurusan Ekonomi Pembangunan, Fakultas Ekonomi, Universitas Negeri Semarang
}

\begin{tabular}{l} 
Info Artikel \\
\hline Sejarah Artikel: \\
Diterima April 2017 \\
Disetujui Juni 2017 \\
Dipublikasikan Agustus \\
2017 \\
\hline
\end{tabular}

Keywords:

Policy, Illegal Housing,

Urbanization, Flood Canal

\begin{abstract}
Abstrak
Tujuan yang akan dicapai dari penelitian ini adalah menganalisis faktor-faktor yang mendorong masyarakat mendirikan dan menghuni permukiman liar, menganalisis solusi yang diberikan Pemerintah sebagai kebijakan penanganan permukiman liar di Sempadan Banjir Kanal Timur Kelurahan Pandean Lamper, menganalisis harapan masyarakat kepada pemerintah yang terkena dampak relokasi. Populasi penelitian ini seluruh penghuni bangunan liar yang berjumlah 643 bangunan dengan sampel 87 bangunan. Penelitian ini menggunakan pendekatan kualitatif dengan data primer. Alat analisis yang digunakan adalah analisis deskriptif persentase dan model kebijakan publik.Hasil penelitian menunjukkan bahwa faktor-faktor yang mendorong masyarakat mendirikan dan menghuni permukiman liar adalah kondisi ekonomi masyarakat yang lemah, aksesibilitas rumah liar yang cukup tinggi, dan kondisi sosial asal daerah masyarakat. Solusi yang diberikan pemerintah untuk menangani permukiman liar adalah melakukan relokasi masyarakat. Namun, masyarakat meminta jaminan dan kompensasi dari pemerintah sebagai bentuk ganti rugi dan kepedulian kepada masyarakat.
\end{abstract}

\section{Abstract}

The aim of this research is to analyze the factors that drive residents to erect buildings and reside in illegal housing, to analyze the solutions that Government give as a policy addressing illegal housing in Sempadan's flood canal Kelurahan Pandean Lamper, to analyze the societal expectations to the government of Semarang city as a result of land eviction. The research's population contain 643 houses and 87 houses for sample. This research use qualitative approach with the use of primary data. Analysis tools for this research is descriptive percentage analysis and public policy model. The results of this research shows that the factors that drives residents to build houses and resides there is weak economic conditions, high illegal housing accessibility, and social condition. The solution that goverment to handling illegal housing is to do relocationg for the residents. But, the residents asked for compensation from the government as a form of social responsibility.

\footnotetext{
${ }^{\bowtie}$ Alamat korespondensi:

Bukit Gading Raya KOMP. Gading Bukit Indah Blok RB No. 18

Jakarta Utara

E-mail: laviniansvin@gmail.com
} 


\section{PENDAHULUAN}

Pembangunan daerah dilaksanakan untuk meningkatkan pemerataan penyebaran pembangunan nasional di seluruh wilayah. Salah satu solusi yang dapat diambil untuk mempercepat pembangunan suatu daerah adalah pengembangan wilayah dengan menetapkan pusat pertumbuhan. Pemusatan pertumbuhan di perkotaan mendorong pergerakan penduduk meninggalkan wilayah tertinggal menuju wilayah perkotaan dan pusat-pusat pertumbuhan. Mc Gee dalam Renggapratiwi (2009) menyatakan perkembangan kota-kota dipengaruhi oleh proses terjadinya urbanisasi yang dapat dilihat dari berbagai aspek demografi, ekonomi, dan sosial.Adanya pertambahan penduduk di perkotaan, berarti pula semakin banyak perumahan yang dibutuhkan tetapi sulit bagi penduduk miskin di daerah perkotaanuntuk membangun rumah di perkotaan yang rata-rata harga lahan di perkotaan cukup tinggi dansemakin meningkat. Padahal rumah merupakan salah satu kebutuhan sangat mendasar bagi manusia (basic need) bersama dengan sandang dan pangan. Legalisasi bersifat selektif bagi pengembang lahan sosio-ekonomi dan politik yang kuat (Morshed, 2014).

Kota Semarang merupakan satu-satunya Kota Metropolis karena jumlah penduduknya melebihi satu juta jiwa dan merupakan kota dengan jumlah penduduk tertinggi diantara kotakota besar di Provinsi Jawa Tengah, yakni sebanyak 1.672.999 jiwa pada tahun 2014. Berdasarkan data dari Badan Pusat Statistik (2015), banyaknya rumah penduduk Kota Semarang tahun 2014 sebanyak 350.528 unit. Banyaknya rumah penduduk di Kota Semarang ini masih belum cukup untuk memenuhi kebutuhan rumah penduduk yang masih tinggi karena Kota Semarang masih membutuhkan sekitar 43.400 unit rumah terutama untuk penduduk yang berpenghasilan rendah.

Menurut Fandari (2015) masalah kemiskinan merupakan fenomena sosial kemasyarakatan yang terdapat di berbagai daaerah. Oleh karena itu, berbagai upaya penanggulangannya telah dilakukan pemerintah melalui pelaksanaan berbagai kebijakaan yang langsung menyentuh kebutuhan hidup masyarakat miskin. Penduduk yang berpenghasilan rendah dan tidak memiliki lahan tempat tinggal terpaksa menempati dan mendirikan bangunan di lahan-lahan kosong yang tidak diperuntukkan untuk kawasan permukiman. Bantaran sungai, pinggiran rel kereta api, dibawah jalan tol ataupun tanahtanah kosong lainya yang biasanya merupakan sebagai tempat yang akhirnya dijadikan penduduk untuk mendirikan rumah untuk tempat berteduh. Keadaan ini juga tampak di sepanjang Sempadan Banjir Kanal Timur Kota Semarang.

Banjir Kanal Timur dan Banjir Kanal Barat merupakan satu paket solusi mengantisipasi banjir dan rob. Seiring dengan berjalannya waktu rupanya telah terjadi pergeseran fungsi maupun pemanfaatannya. Namun, saat ini Banjir Kanal Barat telah dinormalisasi. Bantaran sungai di sekitar terlihat bersih, ditata menjadi jalur dengan beberapa taman dan dimanfaatkan menjadi kawasan wisata di Banjir Kanal Barat Kota Semarang. Berbeda lagi dengan Sempadan Banjir Kanal Timur Kota Semarang yang terdapat banyak bangunan liar. Adapun Daftar Bangunan di Sepanjang Sempadan Banjir Kanal Timur Kota Semarang Tahun 2015 dapat dilihat pada tabel 1.

Lahan Sempadan Banjir Kanal Timur Kota Semarang tidak diperuntukkan untuk kawasan permukiman penduduk. Peraturan Daerah Kota Semarang Nomor 14 Tahun 2011 tentang Rencana Tata Ruang Wilayah Kota Semarang Tahun 2011-2031 merupakan salah satu yang mengatur ketentuan umum zonasi pada sempadan sungai Kota Semarang. Pada pasal 118 ayat 3 poin $b$ tertera 'dilarang mendirikan bangunan pada kawasan sempadan sungai'. Akan tetapi keadaan di lapangan tidak sesuai dengan harapan dan peraturan tersebut. 
Lahan Sempadan Banjir Kanal Timur telah

banyak dibangun rumah-rumah penduduk.

Tabel 1. Daftar Bangunan di Sepanjang Sempadan Banjir Kanal Timur Kota Semarang Tahun 2015

\begin{tabular}{|c|c|c|c|c|}
\hline \multirow{2}{*}{ No. } & \multirow{2}{*}{ Kelurahan } & \multirow{2}{*}{ Kecamatan } & \multicolumn{2}{|c|}{ Jumlah Bangunan Liar } \\
\hline & & & Kelurahan & Kecamatan \\
\hline 1. & Sendang Mulyo & Tembalang & 0 & \\
\hline 2. & Kedungmundu & Tembalang & 38 & 190 \\
\hline 3. & Sendangguwo & Tembalang & 152 & \\
\hline 4. & Pedurungan Kidul & Pedurungan & 234 & \\
\hline 5. & Gemah & Pedurungan & 349 & 583 \\
\hline 6. & Karang Tempel & Semarang Timur & 374 & \\
\hline 7. & Rejosari & Semarang Timur & 263 & \\
\hline 8. & Bugangan & Semarang Timur & 121 & 1151 \\
\hline 9. & Kemijen & Semarang Timur & 58 & \\
\hline 10. & Mlatiharjo & Semarang Timur & 335 & \\
\hline 11. & Lamper Tengah & Semarang Selatan & 229 & \\
\hline 12. & Lamper Lor & Semarang Selatan & 93 & 358 \\
\hline 13. & Peterongan & Semarang Selatan & 36 & \\
\hline 14. & Gayamsari & Gayamsari & 208 & \\
\hline 15. & Pandean Lamper & Gayamsari & 643 & \\
\hline 16. & Sambirejo & Gayamsari & 212 & \\
\hline 17. & Sawah Besar & Gayamsari & 229 & 1614 \\
\hline 18. & Kaligawe & Gayamsari & 205 & \\
\hline 19. & Tambak Rejo & Gayamsari & 117 & \\
\hline 20. & Terboyo Kulon & Genuk & 56 & 56 \\
\hline 21. & Tanjung Mas & Semarang Utara & 145 & 145 \\
\hline Jumlah & & - & 4.097 & 4097 \\
\hline
\end{tabular}

Sumber: Balai Besar Wilayah Sungai Pemali Juana, 2016

Berdasarkan data yang diperoleh dari Balai Besar Wilayah Sungai Pemali-Juana, pada tahun 2015 sebanyak 4.907 bangunan liar yang berdiri di Sempadan Banjir Kanal Timur Kota Semarang. Terdapat 21 Kelurahan dari 6 Kecamatan di Kota Semarang yang dilewati Banjir Kanal Timur dan hampir semua Sempadan Banjir Kanal Timur Kota Semarang terdapat bangunan liar baik di tanggul kanan maupun tanggul kiri. Kelurahan Pandean Lamper, merupakan kelurahan yang terdapat paling banyak jumlah bangunan liar dibanding kelurahan lain, yakni sebanyak 643 bangunan liar. Bukan hanya dari jumlah bangunan liar yang paling banyak dibanding kelurahan lain, Sempadan Banjir Kanal Timur Kelurahan Pandean Lamper juga merupakan Kelurahan yang terdapat bangunan paling banyak yang digunakan unntuk permukiman penduduk. Berdasarkan informasi yang diperoleh dari Ketua Pembina Anak Jalanan Sempadan Banjir Kanal Timur Kelurahan Pandean Lamper, terdapat 525 kepala keluarga yang menghuni rumah di Sempadan Banjir Kanal Timur Kelurahan Pandean Lamper. Resiko dan bahaya banjir kapan saja bisa terjadi akibat dari meluapnya air Banjir Kanal Timur karena terhambat lajunya karena banyaknya bangunan liar. Banjir Kanal Timur Kota Semarang juga bermasalah dengan sedimentasi yang tinggi sehingga membuat kapasitas alur sungai berkurang. Selain itu, berdasarkan Rencana Kerja Pemerintah Kota Semarang Tahun 2016 terkait penataan ruang, masalah yang dihadapi adalah pengendalian 
bangunan liar. Ini menyoroti hubungan antara perumahan dan kursus hidup, kesehatan, pendidikan, dan status sosial (Forres, 2015)

\section{METODE PENELITIAN}

Jenis data yang digunakan dalam penelitian ini adalah data primer dan data sekunder. Data yang langsung diambil dari sumbernya (responden) dan masih bersifat mentah karena belum diolah. Data sekunder yang digunakan dalam penelitian ini bersumber dari BPS, file dari Kementerian Perumahan Rakyat Direktorat Jenderal Sungai Balai Besar Wilayah Sungai Pemali-Juana. Lokasi penelitian ini yaitu Sempadan Banjir Kanal Timur Kelurahan Pandean Lamper dengan sampel berjumlah 87 rumah liar. Fokus Penelitian dalam penelitian ini adalah faktor-faktor yang mendorong masyarakat mendirikan dan menghuni permukiman liar dan solusi penanganan permukiman liar sebagai bentuk kebijakan dari pemerintah Kota Semarang. Adapaun metode pengumpulan data yang digunakan dalam penelitian ini adalah: metode obeservasi, wawancara dan kuesioner.metode kuesioner dilakukan kepada masyarakat penghuni permukiman liar sedangkan metode wawancara dilakukan pada Balai Besar Wilayah Sungai Pemali-Juana. Metode analisis yang digunakan ialah deskriptif persentase dengan pendekatan kualitatif.

\section{HASIL DAN PEMBAHASAN}

Analisis deskriptif persentase digunakan untuk melihat seberapa besar persentase faktorfaktor yang mendorong masyarakat mendirikan bangunan yang dibahas dalam penelitian ini. Hasil analisis deskriptif persentase yang didapat adalah sebagai berikut:

Tabel 2. Persentase Kondisi Ekonomi

\begin{tabular}{llll}
\multicolumn{4}{c}{ Masyarakat } \\
\hline No. & Pendapatan/Bulan & Frekuensi & $(\%)$ \\
\hline 1. & $500.000-1.000 .000$ & 52 & 59,77 \\
2. & $1.000 .000-2.000 .000$ & 26 & 29,89
\end{tabular}

$\begin{array}{llll}\text { 3. 2.000.000 - 3.000.000 } & 5 & 5,75 \\ 4 . \quad>3.000 .000 & 4 & 4,60 \\ \text { Jumlah } & 87 & 100\end{array}$

Sumber: Hasil Pengolahan Data Penelitian, 2016

Hasil diatas menunjukkan bahwa masyarakat permukiman Sempadan Banjir Kanal Timur Kelurahan Pandean Lamper yang memiliki pendapatan antara Rp. 500.000,00 - Rp. 1.000.000,00 per bulan sebesar $59,77 \%$ atau sebanyak 52 responden. Masyarakat yang berpendapatan antara Rp. 1.000.000,00 - Rp. 2.000.000,00 per bulan adalah sebesar 29,89\% atau sebanyak 26 responden. Kemudian sebesar $5,75 \%$ masyarakat yang bependapatan antara Rp. 2.000.000,00 - Rp. 3.000.000,00 per bulan, sementara itu yang berpendapatan $>\mathrm{Rp}$. $3.000 .000,00$ per bulan hanya sebesar $4,60 \%$.Status pekerjaan responden didominasi oleh jenis pekerjaan tidak tetap artinya pendapatan yang diperoleh responden setiap harinya atau setiap bulannya tidak tetap. Hal ini berlaku untuk jenis pekerjaan seperti supir taksi, tukang ojek, wirausaha, buruh bangunan, dan lain sebagainya. Kondisi ekonomi masyarakat yang lemah atau masyarakat miskin ini disebabkan tingkat pendidikan yang rendah, keterampilan yang rendah sehingga pada akhirnya mengakibatkan pendapatan yang mereka terima relatif rendah. Sebanyak $59,77 \%$ masyarakat yang mempunyai pendapatan dengan kisaran hanya hingga Rp.1.000.000,00 per bulan dan dapat diketahui bahwa kondisi ekonomi masyarakat tersebut lemah. Hal ini menunjukkan kondisi ekonomi masyarakat merupakan salah faktor pendorong masyarakat menghuni permukiman liar di sempadan sungai Banjir Kanal Timur Kelurahaan Pandean Lamper.

Tabel 3. Persentase Aksesibilitas Masyarakat Berdasarkan Jarak Ke Lokasi Kerja Sumber: Hasil Pengolahan Data Penelitian, 2016

Berdasarkan tabel. 3, sebagian besar lokasi kerja masyarakat permukiman di sempadan banjjir kanal timur Kelurahan Pandean Lamper 
dekat dengan permukiman mereka. Jarak ke lokasi kerja masyarakat $<2 \mathrm{~km}$ sebesar $45,98 \%$, dalam hal ini masyarakat yang lokasi kerjanya paling dekat adalah pedagang, penjahit dan petugas kebersihan. Jarak ke lokasi kerja $2 \mathrm{~km}-$ $6 \mathrm{~km}$ sebesar $45,98 \%$, yaitu masyarakat yang bekerja sebagai pengumpul barang begas, becak, pengemis, pengamen, dan lain-lain. Jarak ke lokasi kerja masyarakat $6 \mathrm{~km}-10 \mathrm{~km}$ sebsear $1,15 \%$, yaitu supir pabrik. Kemudian jarak lokasi kerja masyarakat $>10 \mathrm{~km}$ sebesar $6,90 \%$ adalah ojek dan buruh buruh borongan yang bekerja hingga ke luar kota.

Berdasarkan jarak rumah menuju lokasi kerja msayarakat permukiman liar Sempadan Banjir Kanal Timur Kelurahan Pandean Lamper dapat dikatakan relatif dekat. Sebagian besar masyakarat menempuh hingga $6 \mathrm{~km}$ untuk mencapai lokasi kerja mereka. Keberadaan permukiman liar Sempadan Banjir Kanal Timur Kelurahan Pandean Lamper yang cukup dekat dengan tempat kerja msayarakat menjadi salah satu alasan masyarakat mendirikan dan menghuni kawasan permukiman liar tersebut. Toleransi pemerintah terhadap ilegalitas adalah fenomena umum namun kurang dipahami (Tanasescu, et al. 2010)

Masyarakat permukiman liar yang identik dengan masyarakat berpenghasilan rendah, yang membeli rumah pun tidak cukup mampu, melihat jarak rumah menuju lokasi kerja relatif dekat menjadi manfaat dan keuntugan tersendiri untuk mereka. Masyarakat bisa menghemat biaya yang dikeluarkan untuk menuju ke lokasi kerja krena kedekatan rumah dengan lokasi kerja. Masyarakat juga merasa Kelurahan Pandean Lamper memiliki askes yang mudah untuk ke berbagai lokasi. Letak permukiman liar Kelurahan Pandean lamper berada di tengah kota, dekat dengan pasar, dan lain-lain.

Selain kedua faktor yang tekah disebutkan diatas yaitu kondisi ekonomi masyarakat dan asksesibilitas, urbanisasi merupakan faktor yang mempengaruhi timbulnya permukiman liar di Kelurahan Pandean Lamper. Berdasarkan hasil penelitian, asal daerah masyarakat di Sempadan Banjir Kanal Timur Kelurahan Pandean

\begin{tabular}{llcl}
\hline No. & Ke Lokasi Kerja & Frekuensi & $(\%)$ \\
\hline 1. & $<2 \mathrm{~km}$ & 40 & 45,98 \\
2. & $2,1 \mathrm{~km}-6 \mathrm{~km}$ & 40 & 45,98 \\
3. & $6,1 \mathrm{~km}-10 \mathrm{~km}$ & 1 & 1,15 \\
$4 . \quad>10 \mathrm{~km}$ & 6 & 6,90 \\
Jumlah & 87 & 100 \\
\hline
\end{tabular}

Lamper, mayoritas merupakan pedatang. Persentase kondisi sosial masyarakat berdasarkan daerah asal dapat dilihat pada tabel 4.

Tabel 4. Persentase Kondisi Sosial Masyarakat Berdasarkan Daerah Asal

\begin{tabular}{lccc}
\hline No. & Daerah Asal Penduduk & Frekuensi & (\%) \\
\hline 1. & Kota Semarang & 29 & 33,33 \\
2. & Luar Kota Semarang & 58 & 66,67 \\
\multicolumn{4}{c}{ Sumber: Hasil Pengolahan Data Penelitian, 2016}
\end{tabular}

Sumber: Hasil Pengolahan Data Penelitian, 2016

Berdasarkan tabel 4, masyarakat permukiman Sempadan Banjir Kanal Timur Kelurahan Pandean Lamper yang merupakan penduduk asli Kota Semarang adalah sebesar $33,33 \%$. Penduduk yang berasal dari luar Kota Semarang yang menghuni permukiman tersebut sebesar 66,67\% yaitu berasal dari Purwodadi, Demak, Kendal, Jepara, Salatiga, Boyolali, Sragen, Temanggung, Klaten, Pati, Kudus, Blora, Pacitan, Ponorogo, Lampung, dan lainlain.Lebih dari setengah $(66,67 \%)$ asal daerah penduduk yang tinggal di permukiman Sempadan Banjir Kanal Timur Kelurahan Pandean Lamper merupakan pendatang dari luar Kota Semarang (Purwodadi, Demak, Kendal, Jepara, Salatiga, Boyolali, Sragen, Temanggung, Klaten, Pati, Kudus, Blora, Pacitan, Ponorogo, Lampung). Arus pendatang yang biasa disebut arus urbanisasi ini menjadikan kota yag sudah padat menjadi semakin padat dengan jumlah penduduk yang semakin meningkat. Peningkatan jumlah penduduk menyebabkan semakin tingginya jumlah permintaan lahan permukiman, yang pada akhirnya akan berdampak pada meningkatnya lahan permukiman. Masyarakat yang tinggal di 
Sempadan Banjir Kanal Timur Kelurahan Pandean Lamper rata-rata sudah tinggal lebih dari 10 tahun.

Motif masyarakat yang merupakan pendatang ke Kota Semarang adalah untuk mencari pekerjaan. Harapannya dengan bekerja di kota, mereka dapat merubah nasib dan mendapatkan pekerjaan yang layak sehingga hidup mereka akan berubah lebih baik dibanding di desa. Keterbatasan lapangan pekerjaan di daerah perdesaan menjadi faktor pendorong penduduk desa pergi meninggalkan desanya. Sedangkan kota khususnya Kota Semarang yang menjadi pusat industri, perdagangan maupun pemerintahan menjadi menjadi faktor penarik penduduk desa datang ke kota. Namun, kenyataanya penduduk yang pidah ke kota Semarang banyak yang kesulitan mendapatkan pekerjaan formal dengan pekerjaan tetap karena latar belakang pendidikan mereka yang rendah, skill mereka juga rendah akhirnya mereka tidak dapat bersaing hidup di kota.

Banyaknya pendatang yang masuk dan tidak terkendali akan berpengaruh pada wajah kota, khususnya masyarakat permukiman Sempadan Banjir Kanal Timur Kelurahan Pandean Lamper, latar belakang pendidikan mereka rendah dan gagal bersaing hidup di Kota Semarang menimbulkan berbagai akibat negatif yaitu munculnya gejala kemiskinan, ketimpangan pendapatan, berakibat pada bertambahnya pengangguran, kriminalitas, bertambahnya lingkungan liar dan kumuh. Arus urbanisasi yang cukup besar tersebut secara tidak langsung berpengaruh terhadap timbul dan berkembangnya permukiman liar terutama di daerah penelitian Kelurahan Pandean Lamper. Kurangnya keterampilan, rendahnya penguasaan ilmu pengetahuan dan pola kehidupan kota yang memaksa masyarakat untuk maju membuat kondisi yang serba terlanjur kekurangan mendorong para pendatang tersebut untuk hidup seadanya, termasuk tempat tinggal yang jauh dari kata layak. Pilihan terakhir mereka ditengah kekurangan tersebut adalah tinggal di daerah permukiman liar.

Berbeda dengan masyarakat yang berasal dari luar kota, masyarakat asli Kota Semarang yang telah hidup di Kota Semarang sejak lahir mempunyai alasan yang sedikit berbeda mengenai latar belakang tinggal di permukiman liar Sempadan Banjir Kanal Timur Kota Semarang. Berdasarkan hasil penelitian, masyarakat asli Semarang pada awalnya mennyewa rumah di sekitar Kelurahan Pandean Lamper. Namun, saat mereka tertimpa himpitan ekonomi mereka melihat peluang bahwa di Sempadan Banjir Kanal Timur masih ada lahan sisa yang bisa dibangun rumah. Masih adanya lahan tersebut masyarakat akhirnya berhenti menyewa rumah formal dan mendirikan rumah di sempadan Kelurahan Pandean Lamper. Kondisi sosial yang meletarbelakangi masyarakat mendirikan bangunan di Kelurahan Pandean Lamper. Kondisi sosial yaitu keterbatasan akses terhadap pekerjaaan, pendidikan, dan asal daerah yang beragam ini yang menyebakan timbulnya permukiman liar.

Kebijakan permukiman liar di Kelurahan Pandean Lamper tersebut, secara formal telah dituangkan kedalam kebijakan seperti Undang-undang permukiman yang merupakan Undang-undang Republik Indonesia Nomor 1 Tahun 2011 tentang Perumahan dan Kawasan Permukiman. Membangun suatu kawasan khusus tempat tinggal terpadu berbentuk vertikal (rumah susun) yang ramah lingkungan untuk disewakan kepada masyarakat yang direlokasi. Metode yang digunakan untuk soulsi adalah model kebijakan untuk penyederhanaan suatu masalah. Permukiman liar ini berkaitan dengan pengenalan problem. Pengenalan problem ini mengadopsi dari A. Jones dalam Parsons, yang menyatakan (2006) "siapa saja yang pertama kali mendefinisikan term awal di mana persoalan itu akan diperdebatkan" kemudian solusi dari kebijakan ini berorientasi pada penyelesaian masalah.

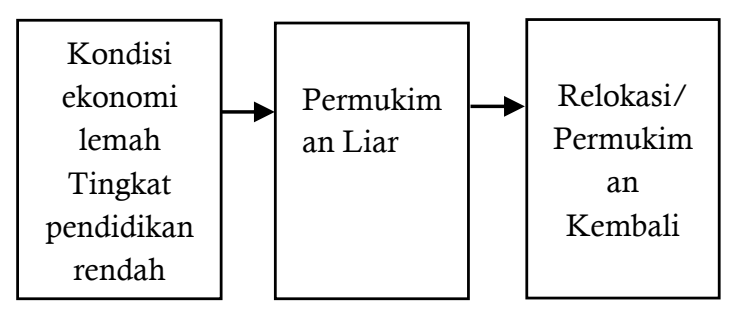


Gambar 1. Model Urutan Substansi Kebijakan Permukiman Liar Banjir Kanal Timur

Sebuah model diatas mengenai urutan substansi kebijakan penanganan permukiman liar di Sempadan Banjir Kanal Timur Kelurahan Pandean Lamper. Kebutuhan perumahan merupakan salah satu kebutuhan pokok hidup masyarakat. Namun, masyarakat kota Semarang masih bannyak yang belum memiliki rumah layak huni dan tinggal di kawasan kumuh dan liar. Permasalahan berawal dari masyarakat yang berada pada kondisi ekonomi yang lemah yaitu masyarakat berpenghasilan rendah masih banyak yang belum memiliki rumah layak huni. Latar belakang tingkat pendidikan masyarakat yang rendah dan rendahnya daya beli masyarakat juga menyebabkan tidak terpenuhinya kebutuhan akan rumah. Kemudian dua faktor diatas didukung oleh keadaan para pendatang atau kaum urban yang berada dalam kondisi serba kekurangan. Adapun model solusi penanganan permukiman liar sempadan banjir kanal timur dapat dilihat pada gambar 2 .

Permukiman yang disiapkan adalah rumah susun sederhana sewa (rusunawa) yang dikelola oleh Pemerintah Kota sendiri. Persiapan permukiman/rusunawa untuk masyarakat menjadi tanggungjawab Pemerintah Kota Semarang yaitu Badan Perencanaan dan Pembangunan Daerah (Bappeda), Dinas Tata Kota dan Perumahan (DTKP), dan Dinas Cipta Karya dan Tata Ruang (Cipka Taru).

Model solusi kebijakan permukiman liar pada gambar. 2, merupakan tahapan yang akan dilaksanakan pemerintah untuk menangani permukiman liar di Sempadan Banjir Kanal Timur Kota Semarang. Dimulai dari sosialisasi, pengadaan tanah dan pemukiman kembali, persiapan permukiman dan pedagang kaki lima, kemudian di eksekusi/relokasi. Hal-hal tersebut merupakan serangkaian langkah dan kesiapan pemerintah untuk menyelesaikan dan mengatasi permasalahan permukiman liar yang berdiri di sepanjang Sempadan Banjir Kanal Timur Kelurahan Pandean Lamper. Sebelum melakukan relokasi terhadap masyarakat penghuni permukiman liar, pemerintah melakukan sosialisasi kepada masyarakat. Sosialisasi ini dilakukan pemerintah untuk mendukung ketepatan terlaksananya kebijakan pemerintah untuk merelokasi warga di permukiman sempadan sungai/anal tersebut. Sosialisasi sangat penting dilakukan agar masyarakat yang terkena dampak penertiban mau dan bersedia pindah ke tempat tinggal yang lebih layak. Hal yang paling penting dari manfaat sosialisasi ini adalah untuk menekan serendah mungkin dan menghindari kemungkinan adanya perlawanan dari masyarakat saat dilaksanakan penertiban.

Namun, yang ditemukan dalam penelitian ini adalah sampai pada waktu pertengahan tahun 2016 ini, masyarakat menyatakan bahwa belum ada sosialisasi yang dilakukan oleh pemerintah terkait penertiban rumah-rumah liar yang mereka huni. Seharusnya sedari awal penanganan permukiman liar ini, pemerintah melibatkan masyarakat yang terkena dampak dalam setiap proses pelaksanaan penanganan. Partisipasi masyarakat dalam pelaksanaan penertiban ini bertujuan untuk menjamin keterlibatan masyarakat dalam pelaksanaan pembangunan agar aspirasi dan kepentingan masyarakat dapat disalurkan dengan baik.

Berbeda dengan solusi dari pemerintah yang akan melakukan pemukiman kembali, masyarakat justru mengharapkan kebijaksanaan. Kebijaksanaan yang diharapkan masyarakat dari pemerintah adalah agar pemerintah tidak melakukan penertiban di kawasan tempat tinggal mereka. Masyarakat sudah merasa nyaman tinggal di permukiman liar tersebut, meskipun permukiman tersebut adalah permukiman yang cukup padat, bangunan semi permanen, cukup kumuh, dan yang terutama adalah permukiman yang berada diatas tanah ilegal. Kebijaksanaan lain yang diharapkan masyarakat yaitu pemerintah memberikan masyarakat kompensasi dan ganti rugi. Kompensasi dalam bentuk uang ataupun ganti rugi dalam bentuk mengganti rumah untuk masyarakat yang terkena dampak. Pemerintah kiranya dapat menemukan titik 
tengah untuk mengatasi dampak yang mungkin akan terjadi.

Gambar 2. Model Solusi Penanganan Permukiman Liar Sempadan Banjir Kanal Timur

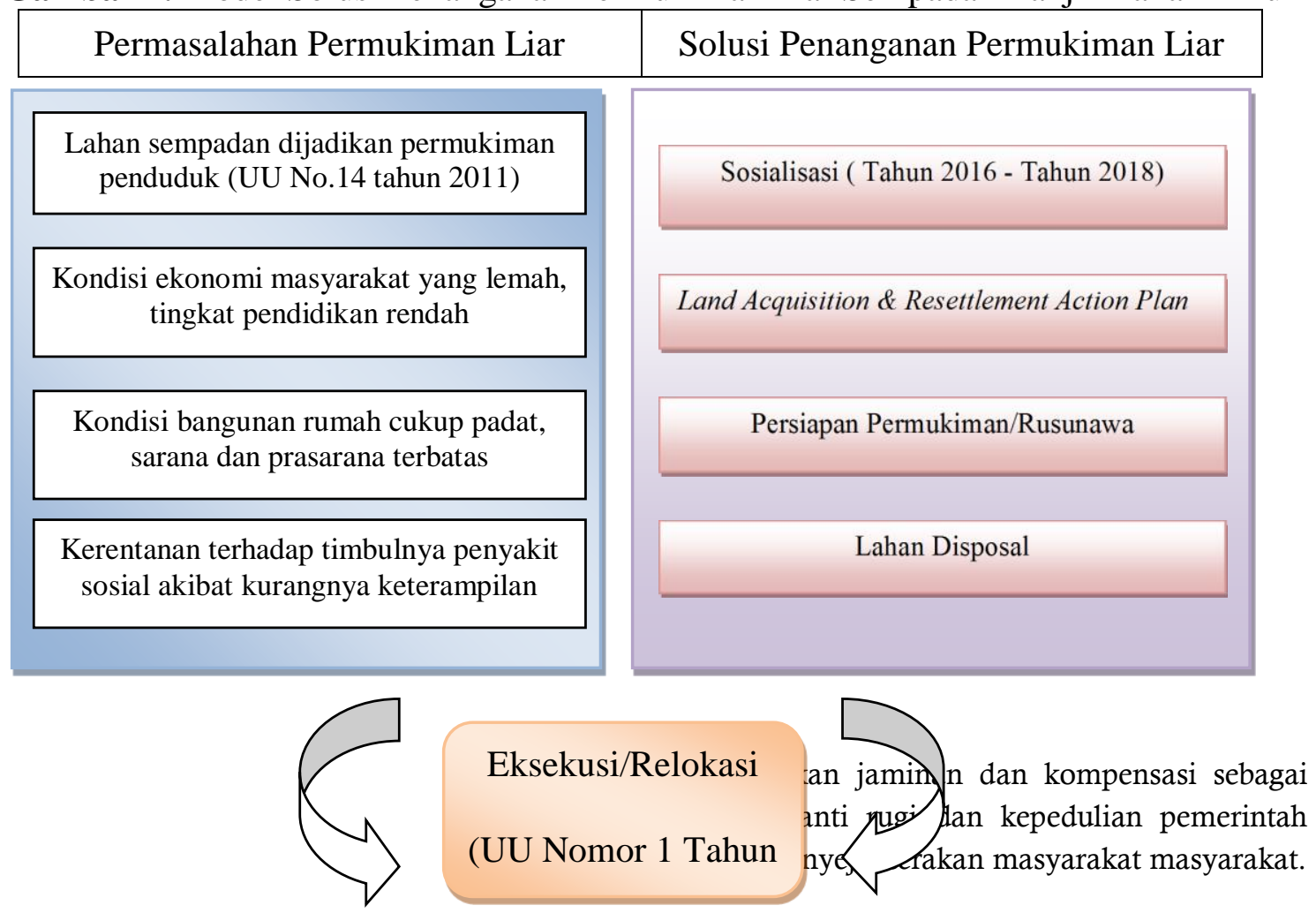

\section{SIMPULAN}

Berdasarkan hasil penelitian Kebijakan Penanganan Permukiman Liar di Sempadan Banjir Kanal Timur Kelurahan Pandean Lamper ialah faktor-faktor yang mendorong masyarakat untuk mendirikan dan menghuni di Sempadan Banjir Kanal Timur Kelurahan Pandean Lamper adalah kondisi ekonomi, aksesibiltas dan kondisi sosial. Solusi dalam menangani permukiman liar di Sempadan Banjir Kanal Timur, kebijakan Pemerintah adalah memukimkan kembali warga ke tempat yang layak huni, yaitu relokasi ke rumah susun sederhana sewa (rusunawa). Walaupun pemerintah memberikan solusi merelokasi masyarakat, tetapi masyarakat permukiman liar berharap pemerintah tidak melakukan penertiban di kawasan tersebut. Masyarakat juga meminta pemerintah untuk
Disarankan (1) pemerintah dapat memberikan sosialisasi dan bantuan kepada masyarakat yang menghuni permukiman liar, seperti pemberdayaan masyarakat ataupun pelatihan kerja. Masyarakat pada umumnya terdiri atas penduduk miskin, keterampilan yang rendah, dan pendidikan rendah yang tidak dapat diserap oleh sektor-sektor formal. (2) Pemerintah sebaiknya dapat mencegah timbulnya permukiman liar. Pencegahan tersebut dilakukan ketika sudah dilaksanakan penertiban terhadap masyarakat yang menghuni permukiman liar di Sempadan Banjir Kanal Timur, kemudian lahan yang ditertibkan tersebut diharapkan segera untuk dimanfaatkan dan dibangun sesuai dengan 
rencana tata ruang publik Kota Semarang, agar lahan kosong publik tersebut tidak digunakan kembali oleh masyarakat yang mengakibatkan menurunnya fungsi kawasan sempadan sungai.

\section{DAFTAR PUSTAKA}

Badan Pusat Statistik. 2015. Jawa Tengah Dalam Angka 2014. Semarang: BPS Jawa Tengah.

BPS kabupaten Semarang . 2014. Kecamatan Jambu dalam Angka 2014. Ungaran : Badan Pusat Statistik

Balai Besar Wilayah Sungai Pemali-Juana. 2015. Study of Dolok-Penggaron River System and Design of East Floodway. Semarang. BBWS Pemali-Juana

Fandari, 2015. Evaluasi Pelaksanaan PNPM Mandiri Perkotaan Program Pinjaman Bergulir Kota Semarang. Economics Development Analysis Journal, 4(4). doi:10.15294/edaj.v4i4.8665

Forrest, Ray. 2015. Housing and Cities. International Encyclopedia of the Social \& Behavioral Sciences (Second Edition), Pages 233-238

Hidayati, Siti, dkk. 2006. Operasional E-Money. Jakarta: Bank Indonesia

Husnaprawira, Rangga. 2014. Pelatihan Melek Keuangan Berbasis Komunitas Bagi Anggota Program Keluarga Harapan Sebagai Langkah Mandiri Penanggulangan Kemiskinan. Karya Tulis Ilmiah Mahasiswa Berprestasi. Depok: Universitas Indonesia

Irmawati, S., Damelia, D., \& Puspita, D. (2013). Model Inklusi Keuangan Pada Umkm Berbasis Pedesaan. Jejak: Jurnal Ekonomi Dan Kebijakan, 6(2). doi: http://dx.doi.org/10.15294 /jejak.v6i2.3885.

Morshed, Md. Manjur. 2014. Illegality of private subdivision and access to land for housing by the urban poor in Dhaka. Habitat International, Volume 44, Pages 386-393.

Peraturan Daerah Kota Semarang Nomor 14 Tahun 2011 tentang Rencana Tata Ruang Wilayah Kota Semarang Tahun 2011-2013.

Renggrapratiwi, Amelia. 2009. "Kemiskinan dalam Perkembangan Kota Semarang: Karakteristik dan Respon Kebijakan". Tesis. Semarang: Fakultas Teknik UNDIP.

Undang-undang Republik Indonesia Nomor 1 Tahun 2011 tentang Perumahan dan Kawasan Permukiman

Tanasescu, Alina, et al. 2010. Tops and bottoms: State tolerance of illegal housing in Hong Kong and
Calgary. Habitat International, Volume 34, Issue 4, Pages 478-484 